\title{
The Effect on Price, Liquidity and Risk When Stocks are Added to and Deleted from a Sustainability Index: Evidence from the Asia Pacific Context
}

\author{
Adrian (Wai Kong) Cheung \\ Department of Finance and Banking, Curtin University \\ Perth, Western Australia, Australia 6102 \\ Tel: + +61-8-92669977, Fax: +61-8-9266 3131 \\ Email: Adrian.Cheung@ curtin.edu.au
}

\author{
Eduardo Roca \\ Department of Accounting, Finance and Economics, Griffith University \\ Nathan, Queensland, Australia 4111 \\ Tel: +61-7-38757583, Fax: +61-7-3875 3719 \\ Email: E.Roca@griffith.edu.au \\ (corresponding author)
}

\begin{abstract}
We examine the impact on returns, risk and liquidity of stocks in the Asia Pacific markets when included into and deleted from the Dow Jones Sustainability World Index over the period 2002-2010. Using an event study methodology, we test five existing hypotheses and two new ones, called the "sustainability taste hypothesis" and "sustainability redundancy hypothesis", which we developed. Consistent with the "sustainability redundancy hypothesis", we find that both index addition and index deletion stocks experience a significant decline in returns, an increase in trading volume, no change in systematic risk and an increase in idiosyncratic risk. This indicates that sustainability matters to Asia Pacific investors, although in a somewhat negative manner.
\end{abstract}

JEL Classification Codes: G15; G14; G19

Keywords

: corporate sustainability; index additions and deletions; Asia Pacific; event study 


\subsection{INTRODUCTION}

The existing literature on index additions and deletions documents strong empirical evidence of positive (negative) permanent (temporary) price impacts upon index addition (deletion) of a firm. At least five different hypotheses have been formulated in the literature to explain the significant price impacts. These are the downward sloping demand curve hypothesis (Shleifer, 1986), price pressure hypothesis (Harris and Eitan, 1986), information cost hypothesis (Merton(1987)), signaling hypothesis (Jain, 1987; Dhillon and Johnson, 1991; Denis, McConnell, Ovtchinnikov and Yu, 2003), and liquidity hypothesis (see Beneish and Whaley, 1996; Hegde and McDermott, 2003).

The first two hypotheses assume that these index addition and index deletion events do not contain information and therefore cannot affect share price. The significant price impacts are due to changes in demand arising from noninformation-based portfolio allocation. The downward sloping demand curve hypothesis posits that the increase in demand is permanent and thus the price and volume impacts so induced are also permanent, while the price pressure hypothesis assumes that the increase in demand can be temporary and likewise the price and volume impacts. Both hypotheses predict that index addition (deletion) stocks experience increase (decrease) in stock returns with higher (lower) liquidity. The other three hypotheses assume that the events carry information and affect the fundamental value of the security through various channels. In particular, the information cost hypothesis argues that index addition 
events can increase investor awareness and decrease information search costs because they make more information available to investors and reduce information asymmetry problems. As a result, investor awareness contributes to the existence of asymmetric price responses where a permanent change in the stock price of added firms is expected after the events but no permanent decline for deleted firms (Chen, Noronha, and Singal (2004)). The signaling hypothesis argues that the events are interpreted by investors as signals regarding the future value of the security because private information possessed by the index company can be revealed by these events. Other things being equal, an expected increase in the future value of the security leads to an increase in security prices. According to the liquidity hypothesis, index addition reduces stock volatility by enhancing the liquidity (as measured by the bid-ask spread) of the market for the underlying stock. Market makers in the stock reduce the bidask spread due to the flow of information-based trading to the stock market, and greater trading activities by hedgers and arbitragers. In other words, the liquidity hypothesis argues that the significant price impacts are due to change in discount rate resulting from change in liquidity risk.

These explanations, however, do not cater to the situation where the stock addition or deletion is in relation to a sustainability index. In contrast to other indices, a sustainability index is one that selects companies based not solely on economic or financial but also on extra-financial considerations such as those that relate to environmental or social performance. It is claimed that, financially, 
investors will be better rewarded investing in "sustainable or socially responsible" companies as these firms will have better financial performance since they represent well-managed firms and are less risky (Renneboog et al., 2008a). These firms also connect better with their different stakeholders, which can translate into more revenues, lower expenses and less risk (Renneboog et al., 2008b). It is also claimed that investors obtain additional utility or satisfaction arising from the additional extra-financial performance by these firms (see, for example, Fama and French, 2007). On the other hand, it is simultaneously argued that investors will be less financially compensated with these "sustainable" firms because these firms can get distracted by the additional goals that they adopt which can then lead to a negative impact on their profitability (Aupperle, Carroll and Hatfield, 1985). Whatever the arguments are, what is obvious is that this type of firms is perceived to be different from traditional firms. Hence, this can affect the way investors react to them when they are listed or delisted from their relevant index.

What happens then if the index involved is one that is a sustainability index? What would be the expected effects on returns, risk, and liquidity when stocks are deleted from and included into a sustainability index? We develop two new hypotheses called the "sustainability taste hypothesis" and "sustainability redundancy hypothesis". The former hypothesis stipulates that investors with tastes or preferences for sustainable firms can derive additional utility from their holdings of the shares of these firms, on top of the utility that they can get from 
the payoffs (or returns) on these shares. The latter hypothesis posits that stock selection based on corporate sustainability is equivalent to imposing "additional or redundant" constraint on portfolio optimistion, other than risk minimization and return maximization, resulting in suboptimal portfolios. We test these two hypotheses as well as the existing five hypotheses in the context of the Asia Pacific region. We undertake our investigation with respect to the stock markets of Australia, Hong Kong (China), India, Japan, Malaysia, Singapore, South Korea, Taiwan and Thailand over the period 2002-2010. We use an event study methodology and the internationally recognised Dow-Jones Sustainability World Index (DJSWI).

The paper is organized as follows. Section 2 discusses the significance and contribution of the paper while Section 3 makes an exposition on the hypotheses being tested in the paper. A discussion of the methodology and data is made in Section 4 and the empirical results are presented in Section 5 . Section 6 discusses the results of the study and also concludes the paper.

\subsection{SIGNIFICANCE AND CONTRIBUTION OF THE RESEARCH}

The question of how investors react to addition and deletion of stocks from a sustainability index is important and interesting as there is now a heightened interest in sustainability among investors or in the so-called socially responsible investing. At present, there is a worldwide movement towards socially 
responsible investing, orchestrated by such international organisations as the United Nations Principles for Responsible Investment (UN PRI), United Nations Environment Program for Financial Institutions (UNEP FI), Carbon Disclosure Project, among others. Furthermore, there is now a very significant amount of investment in sustainable firms. The so called "socially responsible investment" (SRI) has grown very substantially over the last 10 years. SRI assets are worth at least US\$2.71 trillion in the United States, as reported by the Social Investment Forum (2007), and C $\$ 503$ billion (US $\$ 471$ billion) ${ }^{1}$ in Canada based on information from the Canadian Social Investment Organisation (2006). In Europe, the UK is the leading SRI market with assets valued at $€ 781$ billion (US\$1.17 trillion) based on data from the European Social Investment Forum (2006). In Asia, the leading SRI market is Japan with up to $¥ 840$ billion (US $\$ 7.3$ billion) ${ }^{1}$ worth of SRI assets (SIF-J, 2007).

However, in spite of this worldwide surge in investor interest on sustainability, there is a dearth of studies which have investigated the issue of index additions and deletions in relation to a sustainability index. As far as we know, there are only two studies of this type - that of Consolandi et al. (2009) and Cheung (2011). Consolandi et al. (2009) explore the reaction of European stock markets to index addition and deletion announcement of the Dow Jones Sustainability Stoxx Index (DJSSI). They show that a sizeable positive reaction is detectable in the case of additions, and a slightly bigger negative reaction in the case of deletions. On the other hand, Cheung (2011) examines the reaction of American 
stock markets to similar announcements of index additions and deletions to the Dow Jones Sustainability World Index (DJSWI). This study finds that on the day of change, index additions (deletion) stocks experience a significant but temporary increase (decrease) in return, with index addition stocks registering a higher increase than index deletion stocks. ${ }^{1}$, These two papers, when viewed together, suggest that the impact of sustainability seems to be region-specific. Furthermore, this issue has not been investigated yet in the Asia Pacific context. The two studies mentioned focused on the US and Europe. This leaves an important gap in the literature. The Asia Pacific is a region that is economically important. It is where the most dynamic and successful companies are located; yet it is not clear how sustainability is taken into account by investors in this region. The Asia Pacific region is currently lagging behind in terms of the size of SRI. SRI is still relatively a small part of the financial markets in Asia, compared to $12 \%$ and $15 \%$ in the UK and US, respectively (Van Heeswiijk, 2004). There is also less availability of sustainable indices in the Asian scene (ASRI, 2009). Despite these, there are, however, certain new developments in this region which point out to a growing interest in sustainability. Adachi (2011) reports that sustainability initiatives have now started to take roots in the Asian countries covered in this paper. The report, for example, points out that Japan is leading the way in Asia in terms of SRI. Japanese pension funds and financial institutions now pay very significant attention to environmental, social and governance (ESG) issues. IChina now leads in a number of environmentally sustainable initiatives such as in alternative energy. A number of Asian

\footnotetext{
${ }^{1}$ DJSSI is a variant of DJSWI with a focus on European firms.
} 
companies are also signatories to worldwide bodies promoting sustainability such as the UN PRI, World Sustainable Business Council and the Equator Principles, among others. Surveys also revealed that investment managers in Asia believe that responsible investment practices will be widely adopted by 2014 (ASRI, 2009). Given these conflicting evidence and signals about sustainability in the Asia Pacific, there is therefore a need to study how investors in Asia react to sustainability issues. Our paper addresses this gap in knowledge.

Our paper contributes to two strands of literature. First, we contribute to the literature on index addition and deletion. We examine this issue in relation to a sustainability index where we develop two additional hypotheses called the "sustainability taste hypothesis" and "sustainability redundancy hypothesis" to explain the possible effects on a stock's performance when it is included into or deleted from a sustainability index. Thus, in our paper, we test two new hypotheses for the first time. Our study is also the first to test the issue of sustainability index addition and deletion in the context of the Asia Pacific region. As mentioned, there are two studies on sustainability index addition and deletion which are closely related to our paper - that of Consolandi et al. (2009) and Cheung (2011). However, unlike our paper, these two studies simply test existing hypotheses on index addition and deletion and do not focus on the Asia Pacific region. $^{2}$

\footnotetext{
${ }^{2}$ Technically speaking, our paper is also different from these two papers in the following ways. Firstly, these two papers do not account for cross-sectional correlation in their study while our paper employs some t-statistics that allow us to control this cross-sectional correlation problem. Secondly, based on Ahern (2009), Cheung (2011) specifies expected return using the
} 
The second contribution of our paper is to the sustainability or socially responsible investment literature. The way investors react when stocks are added or deleted to a sustainability index can provide an indication as to how and whether investors value "sustainability". Although there is now a significant body of literature on this topic, there is no clear agreement yet as to how investors are rewarded with regards to their investment in sustainable companies. In the US and Europe, there is evidence that investors in SRI are rewarded more than those in conventional investments. However, in Asia, some studies have yielded results showing that investors in sustainable firms are penalised (Renneboog et al 2008b). Despite these negative results on sustainability, as discussed earlier, there are some encouraging developments pointing to a resurgence of interest in sustainability in China, Japan, and Korea which may indicate that the SRI reward landscape in Asia may be changing. Another gap in the literature on sustainability and socially responsible investment is the paucity in research pertaining to the behaviour of sustainable firms' stocks in terms of systematic, risk and liquidity when they experience an event such as being added or deleted from a sustainability index. This kind of studies is very useful in understanding sustainability as they can provide more direct evidence as regards how investors value sustainability by looking at different dimensions in a stock's performance.

characteristics-based benchmark model (a variant of factors model) for U.S. stocks. However, Fama and French (2011) clearly show that factors models are not applicable globally including the Asia Pacific region. They suggest that the CAPM is relatively better than the factors models in explaining cross-sectional returns in Asia Pacific region. Consistent with this finding, our paper uses the market model to estimate expected return and systematic risk. 
Presently, particularly in the context of the Asia-Pacific region, there is no study yet of this type that has been conducted.

\subsection{HYPOTHESES DEVELOPMENT}

In Section 1, we stated that there are five existing hypotheses which explain the effects of index addition and deletion on a stock's price, liquidity and risk. We also stated that the existing literature on index additions and deletions documents strong empirical evidence of positive (negative) permanent (temporary) price impacts upon index addition (deletion) of a firm. We pointed out, however, that these hypotheses do not distinguish whether the index that is involved is one that is a "sustainability" index. This kind of index, such as for example the DJSWI (which is discussed in Section 4), is very significantly different as it selects companies based on how well they perform in relation to certain criteria that include non-financial considerations such as those relating to social and environmental outcomes. As mentioned in Section 1, there is no

strong conclusion yet as to whether investors value these "companies" positively or negatively. Thus, it is not clear how investors will react when companies are added or deleted to a sustainable index.

We therefore develop two additional hypotheses that may explain the behaviour of stocks when added into (deleted from) a sustainability index. First, we present what we call the "redundancy hypothesis". Langbein and Posner (1980) argue 
that investment in corporate sustainable stocks is inconsistent with modern portfolio theory. This view implicitly assumes that investors are rational in the sense that they choose asset holdings based solely on anticipated payoffs in relation to risk and returns. Companies that engage in corporate sustainability activities may earn lower returns because these activities are costly and/or do not maximize the interest of shareholders' interest - only those of stakeholders and agents. For example, Waddock and Graves (1997) argue that a strategic investment in pollution-control system beyond regulatory requirements may put the firm at a competitive disadvantage if other firms do not follow suit. Studies such as those of Balotti and Hanks (1999), Brown Helland, and Kiholm-Smith (2006), show that agency costs play a major role in corporate philanthropic practices, suggesting that managers make charitable donations to further their own objectives and community status. Stock selection based on corporate sustainability is therefore equivalent to imposing "additional" constraint on portfolio optimization, other than risk minimization and return maximization. resulting in suboptimal portfolios. In other words, investing in corporate sustainable stocks may not be the optimal decision because of the redundant constraint imposed by corporate sustainability. Consistent with this view, Renneboog et al. (2008b) report evidence that SRI funds in Asia-Pacific countries strongly underperform their domestic benchmark portfolios by about $5 \%$ per annum. The implication is that prices of stocks are expected to fall (increase) after announcement on index additions and deletions. 
The second hypothesis that we offer is what we term as the "corporate sustainability taste hypothesis". The redundancy hypothesis ignores the possibility that investors may have tastes for sustainable firms on various grounds like religion, morality, loyalty, etc. In theory, investors with tastes for sustainable firms can derive additional utility from their holdings of the shares of these firms, on top of the utility that they can get from the payoffs (or returns) on these shares. This view is particularly relevant to the Asia-Pacific region where people there are perceived to be moralistic than those in Western countries (Tanimoto, 2004; Ho, 2006). Their preference or taste for corporate sustainable stocks implies that prices on these stocks will rise (fall) after when they are newly included into (deleted from) a sustainability index.

Both hypotheses predict that liquidity will improve because trading activities of corporate sustainable stocks are expected to increase at least in the short run.

Index deletion stocks may behave in a way not consistent with the predictions of the taste hypothesis and redundancy hypothesis. This is due to the way Dow Jones selects the stocks to be deleted from the index - only the top $10 \%$ of stocks, in terms of sustainability ratings, are included in the index and the rest $(90 \%)$ of the stocks are therefore deleted. Hence, when a stock falls below the top $10 \%$, a stock gets deleted. Thus, when a stock is deleted it is not clear to investors whether its ranking has now gone down to being, for example, (a) in the $11 \%$ spot (or in the bottom $89 \%$ ), or (b) in the $60 \%$ spot (or in the bottom $40 \%$ ). 
In this example, investors may regard the latter - situation (b), as a case of a stock being deleted because of its absolute relative sustainability performance and they will react according to the prediction of the two hypotheses that we proposed- that is, the price of the deleted stock will decrease. However, in the case of the former - situation (a), investors may not be clear as to how to react. Thus, whenever a stock is deleted, it creates uncertainty as regards investors' reactions. It takes time before investors are able to figure out whether a stock is being deleted because of situation (a) or situation (b). This uncertainty may lead to temporary or even opposite deviation of stock prices from the prediction of our two hypotheses. In the meantime, because of this uncertainty, the index deletion stock experiences an increase in volatility.

In summary, the "redundancy hypothesis" and "sustainability taste hypothesis" predict that share prices of stocks will decrease and increase, respectively, for those newly included into a sustainability index. However, for index deletion stocks, the predictions of these two hypotheses with regards to price movements are ambiguous, especially in the short run. Both hypotheses, however, clearly predict that the liquidity of both index addition stocks and index deletion stocks are expected to improve at least in the short run. In this paper, we test these two new hypotheses together with the five existing hypotheses to determine how investors react when stocks are added or deleted from a sustainable index. The 
results of the tests will also provide an indication as to how investors value sustainability.

\subsection{DATA AND METHODOLOGY}

We investigate the stock price movements surrounding the companies that have been newly included or deleted from the internationally well-regarded Dow-Jones Sustainability World Index (DJSWI) over the period 2002-2010. DJSWI was first published on September 8, 1999, and was the first global index to track the performance of companies that lead the field in terms of corporate sustainability. DJSWI is internationally recognized for its informational transparency and objectivity and well received by international investment communities. ${ }^{3}$ Each year, $10 \%$ of the leading sustainability companies in different sectors are selected from 2500 global companies. A well-defined set of criteria and weightings is used for company selection. Companies are assessed based on the opportunities and risks they face in the economic, environmental and social dimensions. ${ }^{4}$

\footnotetext{
${ }^{3}$ Currently there are 19 countries where more than 70 asset managers are authorized licensees to manage over US $\$ 8$ billion based on the Dow Jones Sustainability Index.

${ }^{4}$ For details, follow the link: http://www.sustainability-indexes.com. There is a similar index called FTSE4Good index that includes US firms as well but its constituent data is not made available to the general public.
} 
The sample period is from 2002 to $2010 .{ }^{5}$ We collect data for the following from the website of DJSWI.

(i) The announcement day of index addition and index deletion events;

(ii) The effective day of index deletion and index addition events ${ }^{6}$; and

(iii) The names of the above companies.

Only those stocks that are listed on the stock exchanges of the nine Asia Pacific countries are selected.

Since index addition and index deletion may affect stock performance in different ways; thus we use three different proxies for stock price movements - abnormal stock returns, risk measures and liquidity. The necessary data is collected from Datastream. Following Campbell, Cowan and Salotti (2010), abnormal returns are defined as the market model prediction errors and quoted in local currencies. ${ }^{7}$ The risk measures tested are systematic risk (as measured by beta), and idiosyncratic risk (as measured by the residual error variance). Two measures are used to capture different aspects of liquidity. The first is trading volume adjusted for market-wide movements which measures changes in

\footnotetext{
${ }^{5}$ The website of DJSWI does not provide any information in relation to the index additions and deletions prior to 2002.

${ }^{6}$ Personal communication to the Director of DJSWI reveals that every announcement is first published on DJSWI website on announcement day at 06:00 CET (05:00 BST/04:00 GMT) and the press release is sent to the media on the same day at 07:15 CET in line with Swiss market regulations. This means that the announcement is made known to the Asia-Pacific financial markets after they close.

${ }^{7}$ Stock returns quoted in U.S. dollars may facilitate effective comparison of abnormal returns in different countries at the expense of embedding the impact of foreign exchange risk, whereas stock returns quoted in local currencies avoid foreign exchange risk but may hinder comparing abnormal returns across different countries. However, Campbell, Cowan and Salotti (2010) report simulation evidence that it is sufficient to use local-currency market model with national market indexes to model abnormal returns in the context of multi-country event study.
} 
volume-driven liquidity. The second is proportional bid-ask spread (PBAS) that aims to capture changes in transaction-cost-driven liquidity. The PBAS for stock i on day $t$ is calculated as follows: ${ }^{8}$

PBAS $_{i t}=\left(\right.$ Ask Price $_{i t}-$ Bid Price $\left._{i t}\right) /\left[\left(\right.\right.$ Ask Price $_{i t}+$ Bid Price $\left.\left._{i t}\right) / 2\right]$

Standard event-study methodology is used to compare these variables before and after index addition (or index deletion) events. Two sets of event days are used; the announcement day (AD) and the day of change (CD). The length between $A D$ and $C D$ varies, ranging from 10 trading days in 2006 to 32 trading days in 2010. For each security, the complete event window runs from 15 days before AD through to 30 days after CD. Following Lynch and Mendenhall (1997), we further divide the full window into six sub-windows in order to assess different aspects of stock behavior around the events. In addition to the standard AD and CD windows, the sub-windows include:

1. Pre-announcement window that lies between $A D-15$ and $A D$.

2. Run-up window that spans from the day after $A D$ through to $C D$.

3. $C D$ windows $(C D+1$ to $C D+5)$ and two post-release windows $(C D+6$, $C D+6)$ and $(C D+6, C D+10)$, respectively.

4. Short-term price impact windows that cover periods within $A D+1$ and $C D+$ 10 and that within $A D+1$ and $C D+30$.

\footnotetext{
${ }^{8}$ We delete those observations with either ask price or bid price being missing.
} 
The pre-announcement window aims to detect the existence of an anticipation effect before the announcement while the run-up window is used to test for possible price changes between $A D$ and $C D$. The three release-related windows allow us to examine the impact of $C D$ on stock prices. The final two sets of windows enable us to distinguish temporary price changes from permanent ones.

For estimation purpose, we divide the sample into two periods with three weeks in between. The first period is called the estimation period that contains observations from $t=-250$ to $t=-16$ while the second period is labeled the event period that starts from $t=0$ to $t=62$ where a relevant window is examined. Abnormal return of stock $i$ is measured as the difference between realized return during the event period and an estimate of its expected (or normal) return in the absence of the event.

$$
A_{u t}=R_{i t}-E\left(R_{i t}\right)
$$

As Fama and French (2011) show that sophisticated model specifications like factor models are applicable to North America but not in the Asia-Pacific, we therefore simply use the market model to compute $E\left(R_{i t}\right)$ :

$$
\begin{aligned}
& R_{i t}=\alpha_{i}+\beta_{i}\left(R_{m t}\right)+\varepsilon_{i t} \\
& E\left(\varepsilon_{i t}\right)=0 ; \quad \operatorname{Var}\left(\varepsilon_{i t}\right)=\sigma_{i}
\end{aligned}
$$

where $R_{i t}$, and $R_{m t}$ are stock returns for company $i$, and the return on the local market index to which company $i$ belongs, respectively. $\varepsilon_{i t}$ is the disturbance term with zero mean and variance $\sigma_{i}$. We estimate beta using data from the estimation period. 
Trading volume of individual stock $i$ is used to measure liquidity. To remove market wide changes from trading volume, we use total trading volume of the stock market of respective countries as proxy for total market trading volume. Consistent with Harris and Gurel (1986), we compute abnormal volume as follows:

$$
A V_{i t}=\frac{V_{i t}}{V_{m t}} \cdot \frac{V_{m .}}{V_{i .}}-1
$$

where $V_{i t}$ and $V_{m t}$ are the trading volumes of security $i$ and of the market portfolio $\mathrm{m}$ at time $\mathrm{t}$, respectively, and $V_{\mathrm{i}}$. and $\mathrm{V}_{\mathrm{m}}$. are the mean trading volumes of security $i$ and of the market portfolio in the 8 weeks before the end of the estimation period. We use the local stock market index to proxy for the market portfolio. ${ }^{9}$ Thus, $A V_{i t}$ is just a standardized trading volume ratio of security $i$, adjusted for market-wide changes in trading volume. This ratio is easy to interpret because if there is no change in trading volume at time t relative to the prior eight weeks, the ratio is expected to be zero.

As there is no appropriate proxy for the bid-ask spread for the market portfolio, PBAS is scaled by its time-series average for similar purpose. The time-series average is estimated from $\mathrm{t}=-55$ to $\mathrm{t}=-16$ (i.e., 8 weeks).

\footnotetext{
${ }^{9}$ We use the market indices constructed by Datastream as proxy for the market portfolio of the nine countries. The Datastream code is "TOTMK ${ }^{* * "}$ where "**" refers to the country code used by Datastream to represent a particular country. For example, the code "TOTMKAU" is used by Datastream to represent the market index of Australia.
} 
To test for the significance of the abnormal return (or volume) over the event period, we use Boehmer, Musumeci and Poulsen's (1991) t statistic adjusted for cross-sectional correlation (hereafter called adjusted BMP test) proposed by Kolari and Pynnonen (2010) and a nonparametric Rank test as calculated in Corrado and Zivney (2002). The former implicitly assumes that the residuals follow normal distribution while the latter does not require that assumption. In addition, Kolari and Pynnonen (2010) report simulation evidence that the Rank test is nearly as powerful as adjusted BMP test.

BMP t statistic is computed as follows:

$$
\begin{aligned}
t_{B} & =\frac{\bar{A} \sqrt{n}}{s} \\
s^{2} & =\frac{\sum_{i=1}^{n}\left(A_{i}-\bar{A}\right)^{2}}{n-1}
\end{aligned}
$$

where $s$ is the cross sectional standard deviation of the scaled cumulative abnormal returns $(A)$ over the sample of $\mathrm{n}$ firms on the event day and $\bar{A}$ is the average of $A$. An advantage of using BMP t statistic is that it accounts for an event-induced variance.

Kolari and Pynnonen (2010) show that in order to avoid the over-rejection problem, it is important to account for cross sectional correlation in an event study. Cross-sectional correlation is particularly relevant to our study since the event day is the same for all firms and thus the scaled abnormal returns are potentially correlated. They demonstrate that the BMP t-statistic adjusted for 
cross-sectional correlation of abnormal returns (i.e., adjusted BMP test) can be computed as follows:

$$
t_{A B}=t_{B} \sqrt{\frac{1-\bar{\rho}}{1+(n-1) \bar{\rho}}}
$$

where $\bar{\rho}$ is the average of the sample cross-sectional correlations of the estimation-period residuals.

\subsection{EMPIRICAL RESULTS}

\section{Summary Statistics}

Panel A of Table 1 displays the frequency of index additions and deletions per year. There are 103 index additions and 75 index deletions. ${ }^{10}$ The total number of events per year varies from a low of 12 in 2004 to a high of 28 in 2002.

[Insert Table 1 here]

As expected, the average of our key variables (i.e., abnormal returns, abnormal trading volume and proportional bid-ask spread) are all close to zero (see Panel B, Table 1). Abnormal returns show very little variation as their standard deviation is around $1.7 \%$ only, while trading volume and bid-ask spread exhibit much higher standard deviations. The former is consistent with the fact that most of the sample stocks are leading companies with small unsystematic risk and the latter is consistent with the view that the variation in (abnormal) trading volume and bid-ask spread are event-driven. Note that all of the key variables are nonnormal as shown in all (sub)samples They all exhibit mild skewness and very

\footnotetext{
${ }^{10}$ Due to data unavailability, the effective number of events is 173 with 100 index additions and 73 index deletions.
} 
high kurtosis, suggesting that we should rely more on the Rank test than the tabmp test because the latter is based on an unwarranted assumption that abnormal returns follow a normal distribution.

We provide some basic information about the sample firms in Table 2. Panel A of Table 2 shows the number firms in the sample and their industry classifications. ${ }^{11}$ They come from seventeen different sectors, including important sectors like industrial (45), financial (25), consumer goods (25), and technology (18). In Panel $B$, it can be seen that the largest group of firms in the sample consists of Japanese firms (51.85\%), followed by Australian firms (22.96\%) and South Korean firms (10.37\%).

\section{[Insert Table 2 here]}

Event studies generally assume that market participants have consensus about how the news should be interpreted. This assumption cannot be warranted when one combines index addition and index deletion events together to do the analysis because market participants may have favorable reaction toward index addition and unfavorable reaction towards index deletion news. To isolate different responses to different events, we classify all index constituent stocks into two groups. The first group consists of stocks that are newly deleted from DJSWI while the second group comprises of stocks that are newly included into the index. The first group therefore represents those stocks that no longer meet

\footnotetext{
${ }^{11}$ The total number of firms (i.e. 184) is not the same as the total number of events (i.e. 178) for two reasons. First, several firms like Fuji Photo Film Ltd, Yamaha Corporation, NEC Corporation, were added and deleted in different years of the sampling period. Second, some firms were classified in different industries over the sampling period.
} 
the sustainability requirements of DJSWI while the second group would proxy those sustainable stocks that are newly recognized by DJSWI.

\section{Index additions}

\section{Price Effects}

We begin by examining trading behavior of index addition stocks first to see whether there is abnormal trading behavior near the announcement day and the day of change. Using the variables described in the previous section, we report cumulative abnormal returns (CARs) in Panel A of Table 3.

[Insert Table 3 here]

Panel A shows that after the announcement, CAR of index addition stocks is usually negative and statistically significant because the Rank test reveals significant results in both $A D$ windows and run-up windows. This also means that on average stock investors value these stocks with a negative bias.

Negative CAR for index addition stocks persists after the day of change as we find similar negative and significant results on the CD windows and other subsequent windows. It is interesting to note that the $t_{a b m p}$ test also reveals significant negative CAR on the day of change and a week after the day of change at conventional significance levels.

\section{Liquidity Effects}


We also do a similar analysis on trading volumes and bid-ask spreads. The idea here is that although opposite interpretations of an event may exist and offset each other resulting in non-significant changes in stock prices, they are also likely to cause an overall increase in trading volumes and/or decrease in bid-ask spread because any trades based on these interpretations may increase trading volumes and/or lower the bid-ask spread.

Panel A of Table 4 reports cumulative abnormal trading volume (CAV) for index addition stocks. We make one important observation with respect to trading volume. In particular, CAV is positive and statistically significant in all of the event windows in Panel A. This means that after controlling for market-driven trades the trading volume is higher than its 8-week time-series averages.

[Insert Table 4 here]

Turning to bid-ask spreads, we construct the cumulative proportional bid-ask spread (PBAS) and report the results in Panel A of Table 5. Two observations can be made about bid-ask spread of index addition stocks. First, it is observed that the bid-ask spread is generally lower in the AD windows as CPBAS is usually negative and statistically significant after the announcement day. One possible explanation is that the spread is narrower because of lower inventory cost and lower adverse-selection cost. ${ }^{12}$ Inventory cost decreases because of a

\footnotetext{
${ }^{12}$ The stock exchanges of the nine countries adopt order-driven trading systems. As in the case of quote-driven markets, bid-ask spread in an order-driven trading system can still be decomposed into different components including inventory cost and adverse selection cost. But the nature of these costs and why they exist are very different from that in quote-driven markets. For a detailed discussion of these differences in the context of FX markets, see McGroaty, Gwilym and Thomas (2008).
} 
high trading volume over the same period (see Panel A, Table 4). Adverseselection cost diminishes because the announcement helps resolve uncertainty. Second, the reduction of the bid-ask spread seems to be a temporary one because the spread is generally greater than zero in subsequent windows, especially in the CD and post-release windows where adjust BMP test also shows statistically significant increase in bid-ask spread.

\section{[Insert Table 5 here]}

\section{Systematic Risk Effects}

We compare systematic risk (as measured by beta) before or after AD (and CD). In estimating abnormal returns, the standard event study methodology suggests that we divide the sample period into two sub-periods. One is estimation period, where beta is estimated, and the other one is event period, where abnormal returns are computed using the beta estimated from the estimation period. For the purpose of estimating systematic risk, this procedure is problematic because the beta that is estimated only represents the systematic risk in the estimation period but not the systematic risk in the event period. In order to estimate the relevant systematic risk, we regress stock returns on the market index in the event period.

Panel A of Table 6 shows the results of the comparison of different ADs where the pre-announcement period is from $t=A D-15$ to $t=A D$, while the postannouncement period is from $t=A D+1$ to $t=C D$. We estimate the betas for these two periods and then use the Chow test to test for stability of beta. We do a 
similar comparison for $C D$ where the pre-change period is from $t=A D+1$ to $t=C D$ and the post-change period is from $t=C D+1$ to $t=C D+30$ and the results are reported in Panel B. Panel $C$ shows the results of a comparison between pre-AD period $(t=A D-15$ to $t=A D)$ and post $-C D$ period $(t=C D+1$ to $t=C D+30)$.

[Insert Table 6 here]

All of these three panels indicate that most of the index addition stocks do not experience any significant change in systematic risk as the number of stocks with significant change in beta is generally less than $5 \%$. The only exception can be found in Panel A where the number of firms with significant decrease in betas is little bit greater than $5 \%$ (i.e., $5.83 \%$ ).

\section{Idiosyncratic Risk Results}

Following exactly the same approach used to generate betas, we compute the residual error variance based on those betas in the event period and use the Ftest to test for stability of residual error variance. Panel $A$ of Table 7 reveals that quite a number of index addition stocks experience changes in idiosyncratic risk after the announcement day. For example, the number of stocks with a significant increase in idiosyncratic risk is sixteen (15.53\%) while those with a significant decrease is eleven (10.68\%) in the AD comparison period. Interestingly, there is a further increase in idiosyncratic risk level after the CD as now the mean difference is 0.003 for index addition stocks, and the number of stocks with a significant increase in idiosyncratic risk (twenty-five) is far greater than the number with a significant decrease (seven). A comparison between 
Panel $\mathrm{A}$ and Panel $\mathrm{C}$ basically confirms the increasing trend in idiosyncratic risk because the total number of index addition stocks with significant increases in risk, jumps up from sixteen to twenty seven while the number with significant decreases in risk falls from eleven to nine.

[Insert Table 7 here]

\section{Index Deletions}

\section{Price Effects}

Unlike index addition stocks whose cumulative abnormal returns are always negative and statistically significant, Panel B of Table 3 depicts a somewhat different picture for index deletion stocks. Now CAR is still negative and statistically significant in the $A D$ windows but becomes positive in the $C D$ and post-release windows as indicated by both adjusted BMP test and Rank test in a post-release window. The change in the sign of CAR is consistent with the view that there is a price reversal.

\section{Liquidity Effects}

CAV of index deletion stocks is greater than zero and statistically significant in the AD windows (Panel B of Table 4). There is strong evidence that the increase in trading volume is a significant one on the day of change because on that day both $t_{a b m p}$ and Rank tests are significant at $10 \%$. Trading volume starts to shrink after the CD windows as CAV turns negative. This is consistent with the view that the increase in trading volume for index deletion stock is a temporary one. 
Panel B of Table 5 shows that the impact of the announcement on the bid-ask spread of index deletion stocks is negative and significant in the AD windows. An analysis of the run-up, CD, and post release windows reveals that the bid-ask spread is significantly larger in size afterwards. The impact manifests itself fully in a wider bid-ask spread as CPBAS turns positive and statistically significant in the CD and post-release windows. The increase in bid-ask spread is likely due to an increase in uncertainty associated with index deletion stocks because DJSWI adopts the "top $10 \%$ selection" approach which allows the possibility that a company may be deleted not because of its poor absolute sustainability performance but because its sustainability scores pale when compared to that of other companies.

\section{Systematic Risk And ldiosyncratic Risk Effects}

Unlike index addition stocks which show little change in systematic risk, a significant number of index deletion stocks experience a decrease in systematic

risk after the $A D$ (see Panel A, Table 6). However, this phenomenon is a temporary one as the number of index deletion shocks with significant decrease in systematic risk drops from thirteen (17.33\%) in Panel A to six $(8.11 \%)$ in Panel B. Panel C basically confirms the same pattern.

In Panel A of Table 7, we note that index deletion stocks generally experience a significant decrease in idiosyncratic risk after the announcement day. Over the 
AD comparison period, the number of index deletion stocks with significant reduction in idiosyncratic risk is thirteen (17.57\%) while only five $(6.76 \%)$ had a significant increase in idiosyncratic risk. A closer look at Panel B reveals that those stocks with significant decrease in idiosyncratic risk fell from thirteen $(17.57 \%)$ to six $(8.11 \%)$ while the number with significant increase in idiosyncratic risk rose from five $(6.76 \%)$ to twenty-five $(33.78 \%)$. Similar results are found in Panel C. The dramatic changes in the number of firms over the AD comparison period and CD comparison period are consistent with the view that the selection process of DJWSI adds another source of uncertainty to the stock market as regards the underlying reason(s) associated with index deletions.

\section{Robustness Checks}

In order to test the robustness of our results, we perform new analyses for each of the following situations. Firstly, we test whether the Global Financial Crisis had significantly driven our results since the sampling period includes 2008-2010 where the GFC occurred. To get rid of the possible impact of GFC on our main results, we redo the analysis on a sample that covers the years 2002 to 2007 only. Secondly, since the Japanese stocks account for $52 \%$, we test whether this has also significantly biased the results. We remove them from the sample and re-do the analysis. We also remove the Australian stocks from the sample because Australia is often perceived to be less Asian and more like other Anglo markets. Finally, we re-examine the robustness of our trading volume measure, 
which is adjusted for market-wide movement in trading volume. We compute trading volume in percentage form and estimate abnormal trading volume as a prediction error of an OLS regression between the trading volumes of an individual stock against that of the stock market. In order to conserve space, we do not present the full results of the robustness test but are available from the authors upon request. Overall, these sub-sample results are also in line with the main results.

\section{Further Robustness Test: Determinants of Abnormal Returns}

Event studies implicitly assume that the significance of abnormal returns is due to the event itself only - in this paper, the addition or deletion of the stock from a sustainability index. Investors, of course, may consider criteria other than sustainability - thus, when a stock is added or deleted to a sustainability index, the investors' reaction that is observed may be due to other factors. . We were hoping, however, that the effects of these other variables on the investors' reaction to each firm in the sample would cancel out to a certain extent because the event study is based on a portfolio of firms rather than on individual firms.

Nevertheless, in order to determine the extent the sustainability factor, as proxied by index addition or deletion, can account for the movement of abnormal returns arising from the event, we test the degree by which some other factors such as liquidity, size and stock price had affected abnormal returns. We also include 
arbitrage risk, as suggested Wurgler and Zhuravskaya (2002), as an additional factor. Under the assumption that there are no close substitutes for corporate sustainability stocks, arbitrageurs who buy or sell corporate sustainability stocks have to face high arbitrage risk, i.e., the risk of hedging with opposite positions in imperfect substitutes for corporate sustainability stocks. As a result of this, they are reluctant to trade around the event date, resulting in a greater jump in the stock price. The less perfect the substitution is between corporate sustainability stocks and other stocks, the higher is the arbitrage risk. To explore the effect of these other potential determinants of abnormal returns, we specify a crosssectional regression as follows:

$$
\operatorname{CAR}_{i}=a_{0}+a_{1} \text { arbrisk }_{i}+a_{2} \text { mktcap }_{i}+a_{3} \operatorname{lnprc}_{i}+a_{4} \text { liquidity }_{i}+\varepsilon_{i}
$$

where $C A R$ is the cumulative abnormal return of security $\mathrm{i}$ from $\mathrm{t}=0$ (i.e., the event date) to $10^{13}$, arbrisk and Inpre refer to arbitrage risk and stock price

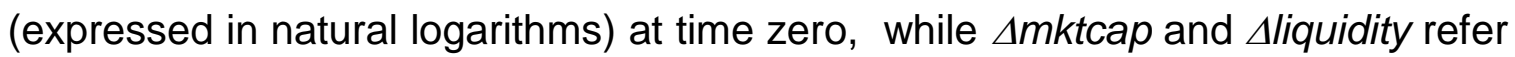
to change in market capitalization and change in liquidity of security $\mathrm{i}$, respectively, over the same time period. Following Wurgler and Zhuravskaya (2002), we measure arbitrage risk as the variance of the residuals from the market model 250 to 15 days prior to the announcement date. We measure liquidity by proportional bid-ask spread. Higher spread means lower liquidity. Two event dates are used. One is the announcement date (AD) while the other one is

\footnotetext{
${ }^{13}$ Ten days are chosen to avoid the possibility of the time span overlapping with the change date.
} 
the change date (CD). The results are reported in Panel A and Panel B of Table 8 , respectively.

Change in market capitalization is consistently found to be able to explain cumulative abnormal returns, regardless of the date and type of event. The regression coefficient of change in market capitalization is also positive; it means that stocks with large change in market capitalization (or size) tend to have large cumulative abnormal returns. Both the stock price on the announcement date and changes in liquidity seem to have temporary effect on CAR. Consistent with the intuition, CAR is decreasing in the stock price but increasing in illiquidity. After the change date, these two variables are no longer statistically significant. Instead, the regression coefficient of arbitrage risk becomes positive and statistically significant, suggesting that stocks with large arbitrage risk are more likely to have large cumulative abnormal returns. This is consistent with the view that corporate sustainability stocks are different from other stocks, making it hard to find perfect substitutes for them.

It should be noted that the combined R-squared for these other variables is 0.535(Addition, AD), 0.339 (Deletion, AD), 0.267 (Addition, $\quad C D$ ) and 0.460(Deletion, $C D$ ), respectively where $A D$ and $C D$ refer to announcement date and change date, respectively. Thus, it is clear that these other variables also affect the investors' reaction to the addition or deletion of a stock to a sustainability index. However, a significant proportion of this reaction is still accounted for by the sustainability factor. This result is consistent with the nature 
of sustainable stocks since they are characterized by financial/economic as well as non-financial, (i.e.sustainability) features. Investors therefore, in their reaction to these stocks, will be guided by both sustainability as well as economic considerations. Consistent with the concept of sustainability or socially responsible investing, the overall results suggest that when stocks are added and/or deleted to a sustainable index, investors react to it based on sustainability as well as economic/financial considerations, such as, for example, size or arbitrage risk.

[Insert Table 8 here]

\subsection{DISCUSSION AND CONCLUSION}

In this paper, we analyze the effects on the performance of stocks that are included into and deleted from the Dow Jones Sustainability World Index (DJSWI) in the context of the Asia Pacific stock markets during the period 2002 to 2010. The effects are measured in terms of stock returns, risks and liquidity.

We find negative and statistically significant abnormal returns for both index addition stocks and index deletion stocks after the announcement day. There is evidence that a price reversal occurs a week after the day of change. Both index addition stocks and index deletion stocks experience an increase in trading 
volume, but the increase in trading volume for index deletion stocks seems to be more significant. However, index deletion stocks experience significant shrinkage in trading volume a week after the day of change, suggesting that the increase in trading volume is a temporary one. Consistent with the results on trading volume, bid-ask spread is generally smaller in size after the announcement day, regardless of types of stocks. However, this becomes wider later after the day of change, implying that the decrease in spread is just transient. The results are consistent with the view that there is a transient increase in liquidity.

Most of the index addition stocks generally experience little change in systematic risk after the announcement day or the day of change. However, some index deletion stocks experience significant decrease after the announcement day, albeit a temporary one. Idiosyncratic risk of both types of stocks significantly changes from the announcement day through to the day of change. First, the apparent paradox that the changes in idiosyncratic risk do not come with any change in systematic risk can be explained by the following formula:

$$
\operatorname{Var}\left(R_{i}\right)=\beta_{i}^{2} \operatorname{Var}\left(R_{m}\right)+\operatorname{Var}(\varepsilon)
$$

where $\operatorname{Var}\left(R_{i}\right)$ represents total risk, $\beta_{i}^{2} \operatorname{Var}\left(R_{m}\right)$ measures systematic risk and $\operatorname{Var}(\varepsilon)$ is unsystematic risk. This equation clearly shows that there are two possibilities consistent with this paradox. One possibility depicts an increase in idiosyncratic risk and hence an increase in total risk. The other possibility suggests that even though there is no change in total risk, the unsystematic risk can change without any change in beta. This is because the market risk $\operatorname{Var}\left(R_{m}\right)$ 
can change at the same time. Second, why is it possible for some index deletion stocks to experience significant increase in idiosyncratic risk while at the same time, other index deletion stocks experience the opposite situation? One possible explanation has to do with the fact that DJSWI selects the top $10 \%$ stocks from 2500 leading companies only. As this approach selects those stocks that are global industry leaders in their sector - i.e., top $10 \%$, a stock, therefore, may be deleted not because it has poor absolute sustainability performance but because its sustainability scores pales in comparison to that of other companies. Without making public the reasons for deletion, the announcement about this by DJSWI leaves an open question for stock markets as to which stocks are being deleted for real sustainability problem. Therefore, it is not unreasonable to see an increase in idiosyncratic risk for some index deletion stocks and a decrease in idiosyncratic risk for other index deletion stocks at the same time because some of the changes will disappear after verification when new information arrives in the stock market. Finally, the evidence of having no change in systematic risk but having one in terms of idiosyncratic risk, implies that sustainability is a nuisance because investors can always diversify it away with a well-diversified portfolio.

These overall results, however, are consistent with the redundancy hypothesis that we formulated. First, the evidence that there is price reversal on index addition stocks and index deletion stocks rule out the downward sloping demand hypothesis and the information cost (investor awareness) hypothesis. The former hypothesis implies that any changes in stock prices must be permanent while the 
latter one suggests not only a permanent change in the stock prices but also a permanent change in liquidity. Second, the finding that index addition stocks experience decrease in stock returns after the announcement day is inconsistent with the price pressure hypothesis which predicts an increase (decrease) in stock returns for index addition (deletion) stocks. Third, the evidence of the existence of asymmetric price responses effect rules out the signaling hypothesis as this hypothesis requires that there is symmetry in the price responses of index addition stocks and index deletion stocks towards the announcement. Fourth, the evidence that there are significant changes in idiosyncratic risk and no change in systematic risk contradicts the liquidity hypothesis which predicts a reduction in stock volatility resulting from a narrower bid-ask spread. Fifth, the evidence on negative CARs for index addition stocks does not support the taste hypothesis. Finally, the evidence that negative CARs and temporary increase in liquidity is consistent with the redundancy hypothesis that predicts decrease in stock prices together with increase in liquidity.

The above findings are robust to the removal of Japanese companies from the sample, the removal of the Global Financial Crisis period, the change in the length of estimation window, the change in the separating period between estimation window and event window, and the change in abnormal trading volume measures. 
Why is it that the "corporate sustainability taste hypothesis" does not hold? There are at least two possible explanations. First, the number of corporate sustainable stocks from those "moralistic" (and therefore with stronger corporate sustainability taste) countries (like Malaysia, Thailand and Taiwan) is small (see Panel B, Table 2). Second, the demand for sustainable stocks in the Asia-Pacific region is not strong enough. To understand this, we employ a framework used in Fama and French (2007) to shed light on this issue. In particular, Fama and French (2007) have identified some conditions where tastes can lead to a large distortion in stock prices. They are:

(1) Investors with tastes on corporate sustainable stocks account for substantial invested wealth;

(2) They have tastes for a wide range of corporate sustainable stocks;

(3) Their investment positions are largely different from those of the market portfolio; and

(4) They under-invest in non-corporate sustainable stocks whose returns are not highly correlated with the returns on corporate sustainable stocks they overinvest.

Based on our earlier discussion, it is clear that the last two conditions are easily satisfied while the first two conditions are not in the Asia-Pacific stock markets. Conditions (3) and (4) are easily satisfied in SRIs because SRIs are expected to hold all of their positions on socially responsible shares and none on non-socially responsible shares. The implications are that the trading volume and the liquidity 
of socially responsible shares are expected to be higher at least in the short run if there is a significant and continual growth in SRls over time. This is the case in emerging markets where SRI managed portfolios grew from $\$ 11,705$ million to $\$ 51,987$ million, representing an increase of fivefold during the period 2003 to 2008 (Mercer, 2009). This means that giving more money to SRI managed portfolios managers will lead them to take larger (smaller) positions in socially responsible shares newly added to (deleted from) DJSWI. ${ }^{14}$

It is noteworthy that not all SRIs invest in a wide range of securities because different SRls use different screening approaches in selecting appropriate investments. Only SRls using a screening approach called best-of-sector approach invest in the most sustainable companies in all sectors, while those utilizing other screening approaches focus only on a subset of companies. Together with the fact that total SRl's managed portfolios only represented $1.55 \%$ of total amount in managed portfolios, this suggests that the extent to which taste for corporate sustainability shares affects share prices is expected to be insignificant and not long-lasting because conditions (1) and (2) are not fully established in emerging stock markets (Mercer, 2009).

Our results therefore show that existing explanations in the literature with regards to the effect of index additions and deletions on the returns, risk and liquidity of stock do not apply when the index is one that is comprised of companies which

\footnotetext{
${ }^{14}$ Note that the effect of index deletion is expected to be small because DJSWI selects the top $10 \%$ of 2500 leading companies in the world based on their relative sustainability performance rather than their absolute sustainability performance.
} 
are chosen by "sustainability" criteria. This means that investors react differently to index additions and deletions when the stocks involved are those of sustainable companies. Consistent with the "sustainability redundancy hypothesis", we find that both index addition and index deletion stocks experience a significant decline in returns, an increase in trading volume, no change in systematic risk and an increase in idiosyncratic risk. This could be taken as evidence that sustainability matters to investors, although in a negative way in the context of the Asia-Pacific markets. As mentioned previously, with respect to European markets, Consolandi et. al (2009) report evidence that index addition stocks experience significant increase in stock returns while index deletions stocks suffer an even bigger decrease in stock returns. On the other hand, in relation to the US markets, Cheung (2011) finds that the increase in stock returns arising from index addition stocks are larger than the decrease in stock returns associated with index deletion stocks. Thus, it seems that Asia Pacific investors behave in a different way than investors in the European and US markets in relation to corporate sustainability which supports our initial hunch that was discussed in the introduction section of this paper. 


\section{REFERENCES}

Adachi, E. 2011. Socially Responsible Investment in Asia. Oekom Corporate Responsibility Review. Oekom Research.

Ahern, K. 2009. Sample Selection and Event Study Estimation. Journal of Empirical Finance 16(3), pp. $466-482$.

Association for Sustainable \& Responsible Investment in Asia (AsRI). 2009. The Time to Lead is Now: The Adoption of ESG Analysis by Asian Government Pension Funds.

Aupperle, K., Carroll, A. and Hatfield, J.. 1985. An Empirical Examination of the Relationship between Corporate Social Responsibility and Profitability. Academy of Management Journal 28, 446-463.

Balotti, R.F. and Hanks, J.. 1999. Giving at the office: a reappraisal of charitable contributions by corporations. The Business Lawyer 55: 965-996.

Beneish, M. and J. Gardner. 1995. Information Costs and Liquidity Effects from Changes in the Dow Jones Industrial Average List. The Journal of Financial and Quantitative Analysis 30(1), 135-157.

Boehmer, E., Musumeci, J. and Poulsen, A.. 1991. Event Study Methodology under Conditions of Event Induced Variance. Journal of Financial Economics 30, 253-272.

Brown, W., Helland, E. and Smith, J.. 2006. Corporate Philanthropic Practices, Journal of Corporate Finance 12, 855-877.

Campbell, C., Cowan, A., and Salotti, V. 2010. Multi-Country Event Study Methods. Journal of Banking \& Finance 34, 3078-3090.

Chen, H., Noronha, G., and Singal, V.. 2004. The Price Response to S\&P 500 Index Additions and Deletions: Evidence of Asymmetry and a New Explanation. The Journal of Finance 59 (4), 1901-1929.

Cheung, A. 2011. Do Stock Investors Care about Corporate Sustainability Evidence from Event Study. Journal of Business Ethics 99, 145-165.

Consolandi, C., Jaiswal-Dale, A., Poggiani, E., and Vercelli, A.. 2009. Global Standards and Ethical Stock Indexes: The Case of the Dow Jones Sustainability Stoxx Index. Journal of Business Ethics 87: 185-197. 
Corrado, C., and Zivney, T.. 1992. The Specification and Power of the Sign Test in Event Study Hypothesis Tests Using Daily Stock Returns. Journal of Financial and Quantitative Analysis 27:465-78.

Denis, D., McConnell, J., Ovtchinnikov, A., and Yu Y.. 2003. S\&P 500 index additions and earnings expectations. Journal of Finance 58, 1821-1840.

Dhillon, U. and Johnson, H.. 1991. Changes in the Standard and Poor's 500 List. The Journal of Business 64(1), 75-85.

Fama, E. and French, K. 2007. Disagreement, Tastes, and Asset Prices. Journal of Financial Economics 83, 667 - 689.

Fama, E. and French, K. 2011. Size, Value, and Momentum in International Stock Returns. Working Paper, Amos Tuck School of Business.

Harris, L. and Eitan, G.. 1986. Price and Volume Effects Associated with Changes in the S\&P 500 List: New Evidence for the Existence of Price Pressures. The Journal of Finance 41 (4), 815-829.

Hegde, S. and McDermott, J. 2003. The Liquidity effects of Revisions to the S\&P 500 Index: An Empirical Analysis. Journal of Financial Markets 6, 413-459.

Ho, B. 2006. Confucian Businessman, CSR Asia Weekly, Vol. 2, Week 43, October 25.

Jain, P. 1987. The Effect on Stock Price from Addition in or Deletion from S\&P 500. Financial Analysts Journal 43(1), 58-65.

Karlsson, J. and Chakarova, Y.. 2008. Does Corporate Social Responsibility Pay off? - An Event Study of the Impact of Corporate Entry and Exit from the Dow Jones Sustainability World Index on the Market Value of a Company. Unpublished Advanced level Thesis, School of Business, Economics and Law, Goteborg University.

Kolari, J. and Pynnonen, S. 2010. Event Study Testing with Cross-sectional Correlation of Abnormal Returns. Review of Financial Studies 23(11), 39964024.

Langbein, J. and Posner, R. 1980. Social Investing and the Law of Trusts. Michigan Law Review 79, 72-112.

Lee, D. and Faff, R. 2009. Corporate Sustainability Performance and Idiosyncratic Risk: A Global Perspective. The Financial Review 44: 213—237. 
Lo, S. and Sheu, H.. 2007. Is Corporate Sustainability a Value-increasing Strategy for Business? Corporate Governance - An International Review 15(2), 345-358.

Lopez, V., Garcia, A., and Rodriquez, L.. 2007. Sustainable Development and Corporate Performance: a Study Based on the Dow Jones Sustainability Index. Journal of Business Ethics 75, 285-300.

LRQA. 2010. CSR in Asia - The Real Picture. LRQA and CSRAsia.

Lynch, A. and Mendenhall, R. 1997. New Evidence on Stock Price Effects Associated with Changes in the S\&P 500. Journal of Business 70, 351-384.

McGroarty, F., Ap Gwilym O., and Thomas, S. 2008. The Components of Electronic Order-Driven Spot FX Bid-Ask Spreads Pre- and Post-EMU. Monograph. University of Southampton. Southampton, UK.

Menz, K. 2010. Corporate Social Responsibility: Is it Rewarded by the Corporate Bond Market? A Critical Note. Journal of Business Ethics 96, 117-134.

Mercer. 2009. Gaining ground - integrating environmental, social and governance (ESG) factors into investment processes in emerging markets. International Finance Corporation (IFC).

Merton, R. 1987. A Simple Model of Capital Market Equilibrium with Incomplete Information. The Journal of Finance 42(3), 483-510.

Orlitzky, M., Schmidt, F., and Rynes, S. 2003. Corporate Social and Financial Performance. Organization Studies 24(3), 403-441.

Patell, J. 1976. Corporate Forecasts of Earnings Per Share and Stock Price Behavior: Empirical Tests. Journal of Accounting Research 14(1), 246-276.

Renneboog, L., Horst, J., and Zhang, C. 2008a. Socially Responsible Investments: Institutional Aspects, Performance, and Investor Behaviour. Journal of Banking and Finance 32, 1723-1742.

Renneboog, L., Horst, J., and Zhang, C. 2008b The Price of Ethics and Stakeholder Governance: Evidence from Socially Responsible Mutual Funds. Journal of Corporate Finance 14, 302-322.

Shleifer, A. 1986. Do Demand Curves for Stocks Slope Down? Journal of Finance 41(3), 579-590.

Tanimoto, K. 2004. CSR Keie, Chuokeizaisha. 
Tsai, C. 2007. The Reputation Effect and Value in Corporate Social Responsbility. Unpublished Master Thesis, Department of Finance, Yuan Ze University, Taiwan.

Van Heeswijk, J. 2004. Greening of Industry Network Conference Corporate Responsibility for Environmental Performance in Asia-Pacific. Manila ADB.

Waddock, S. and Graves, S. 1997. The Corporate Social Performance-Financial Performance Link, Strategic Management Journal 18, 303-319. 